\title{
Liability for Transboundary Damage of Genetically Modified Organisms: Existing Patterns and Application
}

\author{
Chunyi Liu \\ China University of Political Science and Law, Beijing, China \\ Email:90liuchunyi@163.com
}

How to cite this paper: Liu, C. Y. (2021). Liability for Transboundary Damage of Genetically Modified Organisms: Existing Patterns and Application. Beijing Law Review, 12, 16-26.

https://doi.org/10.4236/blr.2021.121002

Received: December 19, 2020

Accepted: February 1, 2021

Published: February 4, 2021

Copyright (อ 2021 by author(s) and Scientific Research Publishing Inc. This work is licensed under the Creative Commons Attribution International License (CC BY 4.0).

http://creativecommons.org/licenses/by/4.0/

\section{(c) (i) Open Access}

\begin{abstract}
Normative analysis found that for the application of liability for transboundary damage to genetically modified organisms, there are currently three liability patterns: traditional state liability, private law liability, and liability for transboundary damage. It will not be an effective solution to the problem of penalty for damages, if the above liability patterns apply to transboundary damage of genetically modified organisms separately. And this approach is inconsistent with the legal principles of relevant international law and judicial practice. So this article uses method of legal interpretation to analyze and interpret the provisions of Convention on Biological Diversity, The Cartagena Protocol on Biosafety and The Nagoya-Kuala Lumpur Supplementary Protocol to clarify the true meaning of the provisions in depth, and eliminate errors and omissions. At the same time, this article uses the method of theoretical analysis to analyze the existing liability patterns. Finally, we found, the principle of timely and adequate compensation for victims should be implemented in complex realities, and genetically modified damage should be dealt with and in accordance with the attributes of damage, causation and other factors. According to these factors, we will divide transboundary damage of genetically modified organisms into three types: intentional transboundary movement, unintentional transboundary movement and illegal transboundary movement. To divide the transboundary damage to genetically modified organisms and apply different liability patterns according to different situations should be the best approach.
\end{abstract}

\section{Keywords}

Genetically Modified Organisms, Transboundary Damage, Liability Patterns, A Hybrid Approach of Liability 


\section{Introduction}

Genetically modified organisms refer to gene sequences that contain and express genes from other species. Genetically modified organisms are produced through genetic engineering, using appropriate vectors to insert the required foreign genes into the host's fertilized eggs or early embryos (Isaac, 2001). Genetically modified biotechnology has broad application prospects and has promoted major progress in the fields of medicine and agriculture. These advancements may include new medical methods and vaccines, new industrial products, and better fibers and fuels. Living genetically modified organisms form the basis of a series of products and agricultural commodities. Common genetically modified organisms include crops that have been genetically modified to increase yield or pest tolerance, such as tomatoes, cassava, corn, cotton, and soybeans, as well as processed products containing genetically modified ingredients, certain vaccines, drugs, food additives, and fuel ethanol Wait.

Genetically modified organisms have the risk of causing damage, so they have aroused widespread public concern. People do not yet fully understand the interaction between genetically modified organisms and different biological systems. If the international community needs to further clarify the risks of genetically modified organisms to biodiversity and human health, at present, such risks include causing unintended changes in other species, thereby unfavorable effects on the ecosystem; weeding caused by genetic drifting of genetically modified crops; potential risks to human health, and the stability of inserted genes. The public has formed opposing views on the risk of damage caused by genetic modification. One of the important reasons for this is the damage to the environment and the human body that may be caused by genetically modified organisms. From international to domestic, damage caused by genetically modified organisms occurs frequently. According to the GMO Registry of Greenpeace, since the establishment of the database in 2005, there have been 396 GMO damage incidents (Wang, 2016). In 2001, the Mexican government reported that the corn grown in the country was contaminated with genetically modified Bt maize, and this type of genetically modified Bt maize was not approved for cultivation in the country (Liu, 2011). Between 2004 and 2005, 23 workers in West Madhya Pradesh, India, experienced varying degrees of allergic symptoms due to exposure to genetically modified cotton. According to another study, since 2002, a total of nearly 200 genetic damage incidents have been discovered, of which 138 have been reported in the three years from 2009 to 2012. Among them, 35 - 45 of the three countries in China, the United States and Canada may cause pollution or among the damaged products, rice and wheat are the most common products, followed by corn and soybeans (Yang, 2014).

The occurrence of damage caused by genetically modified organisms is not limited to a specific country, but often crosses national boundaries. Such damage is called transboundary damage of genetically modified organisms. The basic rule for transboundary damage of genetically modified organisms mainly comes 
from the "Convention on Biological Diversity", "Cartagena Protocol on Biosafety" and the "Cartagena Protocol on Biosafety on Liability and The Nagoya-Kuala Lumpur Supplementary Protocol on Remediation. The above-mentioned international legal documents have made principled provisions on the scope and distinction of transboundary damage from genetically modified organisms.

As mentioned above, "Cartagena Protocol on Biosafety" defines genetically modified organisms as: refers to any living organism with a novel combination of genetic materials obtained through modern biotechnology. The protocol also defines terms such as "living organisms" and "modern biotechnology". In various texts, genetically modified organisms are also referred to as living genetically modified organisms. According to the agreement, the concept of transboundary damage of genetically modified organisms can be defined as:"The transfer of genetically modified organisms from one contracting party to another contracting party or the transfer of genetically modified organisms from one contracting party to a non-contracting party, resulting in negative Effects to protection of biodiversity and human health." The supplementary protocol further clarifies this definition, increasing the damage caused by the transboundary movement of genetically modified organisms from non-parties, that is, the damage caused by the transboundary movement of genetically modified organisms between any countries. It should be regarded as transboundary damage of genetically modified organisms in the sense of international law.

At present, regarding the application of liability for transboundary damage to genetically modified organisms, there are ambiguities in the relevant regulations, and there are also disputes in academia. Therefore, the application of liability for transboundary damage of genetically modified organisms is an urgent problem to be solved. There are three different patterns of liability in international law: Traditional state liability pattern, Transboundary damage liability pattern and civil liability pattern. Some scholars believe that civil liability should be applied to transboundary damage of genetically modified organisms, and some scholars advocate the application of state liability. So the similarities and differences of these liabilities compared in this article, and pointed out that the sole application of any liability model cannot perfectly solve the problem of transboundary damage to genetically modified organisms. It is a feasible path to distinguish between various situations of transboundary damage of genetically modified organisms and apply different liabilities.

\section{Regulations Basis for Transboundary Damage of Genetically Modified Organisms}

At the level of international law, the norms related to the liability for transboundary damage of genetically modified organisms are the Convention on Biological Diversity, the Cartagena Protocol on Biosafety and the Nagoya-Kuala Lumpur Supplementary Protocol on Liability and Remedy to the Cartagena Protocol on Biosafety. 


\subsection{Convention on Biological Diversity}

The Convention on Biological Diversity is the basic norm for liability for damages related to transboundary movement of genetically modified organisms. In its preamble, the Convention on Biological Diversity states: "Parties are aware of the value of biodiversity, Recognizing that the protection of biodiversity is a common concern of all mankind, reaffirming that each country has sovereign rights over its own biological resources, and reiterating that each country has the responsibility to protect its own biological diversity and use its own biological resources in a sustainable manner, Expecting to strengthen and supplement the existing international arrangements for the protection of biodiversity and the sustainable use of its components; and is determined to protect and sustain the use of biodiversity for the benefit of present and future generations (Lin, 2011). This article points out the value of biodiversity and states that each country has the responsibility to protect its own biodiversity. The third principle of the Convention on Biological Diversity states: "In accordance with the UN Charter and the principles of international law, countries have the sovereign right to develop their resources in accordance with their environmental policies, and they are also responsible for ensuring activities within its jurisdiction or control. It shall not cause damage to the environment of other countries or the environment outside the scope of national jurisdiction (Lin, 2011)." This article clarifies the obligation of each country to ensure that activities under its control or jurisdiction should not cause damage. This article clarifies the first-level obligations of transboundary movement of genetically modified organisms.

\subsection{The Cartagena Protocol on Biosafety and the Nagoya-Kuala Lumpur Supplementary Protocol}

The Cartagena Protocol on Biosafety and the Nagoya-Kuala Lumpur Supplementary Protocol on Liability and Redress are the implementing norms for the liability for transboundary damage of genetically modified organisms. The Cartagena Protocol on Biosafety states in its Article 27: "The Conference of the Parties serving as the meeting of the Parties to this Protocol shall, at its first meeting, initiate a The process of international rules and procedures regarding liability and remedies for damage caused by the transfer, while analyzing and referring to the current work on such matters in the field of international law, and striving to complete this process within four years." Article 27 of The Cartagena Protocol on Biosafety clarifies that the "Supplementary Protocol" is an international rule applicable to compensation and remedies for damage caused by the transboundary movement of genetically modified organisms.

Article 11 of the "Supplementary Protocol" stipulates traditional state responsibilities, which clarifies that the "Supplementary Protocol" does not affect traditional state responsibilities under general international law. As far as liability for transboundary damage is concerned, Article 16 of the Supplementary Protocol states: "Without prejudice to paragraph 3 of this Article, this Supplementary 
Protocol shall not affect the rights and obligations of the parties under international law." The Supplementary Protocol does not affect the right of the injured country to claim responsibility for transboundary damage from the country of origin in accordance with general international law. The "Supplementary Protocol" clearly stipulates in Article 12, paragraph 1: that Contracting Parties shall establish domestic law procedures and rules for compensation for damages, and may apply civil liability according to the circumstances. It can be seen that the "Supplementary Protocol" has an optional attitude towards the three patterns of liability and is open to the application of different patterns of liability (Watanabe, 2015).

\section{Liability Patterns for Transboundary Damage of Genetically Modified Organisms}

For the relief of damage caused by the transboundary movement of genetically modified organisms, a specific liability pattern is generally used for relief. However, due to the characteristics of this damage itself, it is in a difficult situation in the application of liability. In order to deal with the problem of transboundary pollution, the International Law Commission has organized special studies on existing relevant international rules for many times, and finally adopted a number of draft articles, and formed several liability patterns accordingly namely: traditional state responsibility, transboundary damage Liability and civil liability.

\subsection{Traditional State Liability Pattern}

Traditional State liability is the earliest pattern of liability in the field of international law, and it is based on the existence of international misconduct. In the "Draft Articles on International liability for Internationally Wrongful Acts" drafted by the International Law Commission, it is believed that a country should bear international liability for its internationally wrongful acts (ILC, 2001). Traditional State liability is also called liability for internationally wrongful acts. As the name implies, it is a kind of behavioral liability. Internationally wrongful acts may also cause genetically modified organisms to cross the border and cause damage, but from the perspective of the transmission mechanism of genetically modified organisms, genetically modified organisms can spread independently of human behavior. It is a natural phenomenon and its occurrence does not exist. Due to human factors, the traditional state liability cannot be applied to the damage caused by the transboundary movement of genetically modified organisms under such circumstances.

\subsection{Transboundary Damage Liability Pattern}

Transboundary damage liabilit is an important pattern of liability to deal with the problem of transboundary pollution, but the scope of damage caused by transboundary movement of genetically modified organisms has actually exceeded the scope of adjustment of liability for transboundary damage. Transboundary damage liability arises when traditional state liability is not sufficient 
to deal with the complex activities of humans in modern society. This pattern of liability originates from the "Damage caused by acts not prohibited by international law" established by the $30^{\text {th }}$ session of the United Nations International Law Commission. On the topic of "State Liability for Sexual Consequences", the UN International Law Commission drafted the "Draft Articles on International Liability for Harmful Consequences Caused by Acts Not Prohibited by International Law" (ILC, 2006). The transboundary movement of genetically modified organisms can be through the mechanism of gene drift, or through international trade. Therefore, the activities that cause damage may occur in the country of origin or in the victim country, that is, activities that cause damage. It may occur before the transboundary movement of genetically modified organisms, or after the transboundary movement of genetically modified organisms. The application of liability for transboundary damage is obviously limited to the hazardous activity occurring in the country of origin. Moreover, the liability for transboundary damage is mainly applicable to "hazardous activities that may cause major damage", while the transboundary movement of genetically modified organisms may be based on many purposes such as scientific research, transportation, production, sales, and use. Many activities are not "may cause Hazardous activities that cause major damage". Therefore, the liability for damage caused by transboundary genetically modified organisms is not entirely within the scope of liability for transboundary damage.

\subsection{Civil Liability Pattern}

Regarding the issue of transboundary pollution, civil liability has received more and more attention from the international community, but it is not enough to apply civil liability to transboundary damage of genetically modified organisms. The "Draft Principles for Distribution of Loss in the Case of Transboundary Damage Caused by Hazardous Activities" introduced by the United Nations International Law Commission introduced civil liability as a means of relief (ILC, 2002). It is stated in Principle 6: "That is, each country should endow its own judicial and administrative departments with the necessary jurisdiction and powers to ensure that the domestic departments can provide relief without affecting the victims' right to seek other relief (ILC, 2006).” The application of civil liability is limited to being able to confirm the causality of transboundary damage caused by genetically modified organisms at the operator level. In many transboundary pollution cases, it is impossible to identify the specific operator that caused the damage. For example, in air pollution, the distance between the pollution source and the polluter is very long, and it is impossible to tell who caused the damage. Therefore, civil liability is difficult to apply to transboundary damage of genetically modified organisms.

\subsection{Comparison of Liability Patterns}

The three patterns of liability mentioned above differ in the subject and standard 
of liability. In terms of subjects, although the subjects of Transboundary damage liability and traditional state liability include many subjects of national law, the most important subject is the state, which means that the two patterns of liability were initially based on the state., And the subject of civil liability does not include the state, mainly natural persons and legal persons outside the state. From the perspective of liability standards, traditional state liability is a kind of behavioral liability. As long as there is an international violation and the behavior can be attributed to the state, the subject should bear the liability. Liability for transboundary damage relies on the damage result, and as long as the result of damage occurs, the subject should be liable. Civil liability may be either behavioral liability or result liability. However, due to the complexity of damage, none of the above types of liability can cover all situations of damage, so we will classify damage below to determine the application of reasonable liability.

\section{Classification of Damage and Application of Liability}

The foregoing and related legal documents have made a variety of distinctions between transboundary damages of genetically modified organisms, but what is related to the liability for transboundary damage of genetically modified organisms is the distinction between intentional transboundary movement, unintentional transboundary movement and illegal transboundary movement (IUCN, 2003). Therefore, transboundary damage to genetically modified organisms before explaining the form of liability, the concepts of intentional transboundary movement, unintentional transboundary movement and illegal transboundary movement must be clarified.

\subsection{Liability for Damage Caused by Intentional Transboundary Movement}

The relevant international legal documents do not directly define the connotation of the concept of "intentional transboundary movement". So it is necessary to summarize the circumstances listed in the document to explain that what kind of behavior belongs to "intentional transboundary movement". In Article 3 of the "Protocol", both the terms export and import of genetically modified organisms are defined as: intentional transboundary movement from one contracting party to another. In other words, the import and export of genetically modified organisms belong to the category of intentional transboundary movement. Paragraphs 1 and 2 of Article 3 of the Supplementary Protocol indicate: genetically modified organisms intended for direct use as food or raw material or processing; genetically modified organisms designated for enclosed use; and authorized transboundary movement of genetically modified organisms intended for intentional introduction into the environment are all belong to intentional transboundary movement. The damage caused by the above three situations is the damage caused by intentional transboundary movement. At the same time, we can see that the above three situations require authorization by the authorities, and this authorization should be based on a specific purpose. There- 
fore, we can conclude that the definition of "damage caused by intentional transboundary movement" is the damage caused by the act of transboundary movement from one party to another party that is authorized by the authorities based on a specific purpose and complies with the domestic measures adopted by the parties to implement the Protocol.

The risk of activities is an important consideration in the form of liability, and the risks of damage to the environment caused by intentional transboundary movement under different purposes are also different. This must be seen from the mechanism set by the Protocol. The "Protocol" sets up corresponding mechanisms according to the different levels of risk in various situations of intentional transboundary movement. The most important of these is the prior informed agreement mechanism set up in Article 7 of the "Protocol". For most transboundary movements of genetically modified organisms, the prior informed agreement mechanism should be applied. However, the "Protocol" makes special provisions for the procedures, transit and closed use of living genetically modified organisms intended to be directly used for food or feed processing. Article 5 of the "Protocol" stipulates that the transit and closed application of genetically modified organisms shall be exempted from prior informed use. Agreement system, but contracting states can make special provisions for the transit and closed use of genetically modified organisms in accordance with their domestic laws. Article 11 of the Protocol also exempts living genetically modified organisms intended to be directly used for food or feed processing from the prior informed agreement system. Instead, a simplified procedure is adopted, that is, related transboundary procedures are transferred through the Biosafety Clearing House. The transfer information is notified to the contracting parties. It should be pointed out that although the above two situations are exempt from the prior informed agreement system, the two situations are not exempt from the risk assessment system, risk management system, information exchange system, and labeling system stipulated in the Cartagena Protocol on Biosafety. Multiple systems. Obviously, it can be seen from the provisions of the "Protocol" that genetically modified organisms that are used in transit and in closed use and intended to be directly used for food or feed processing are less likely to cause damage than genetically modified organisms under other uses.

According to the definition of damage caused by intentional transboundary movement in the previous article, we know that such transboundary movement is authorized by the state. Therefore, the change can be attributed to the state and meets the requirements of traditional state responsibility. When the intentional transboundary movement of genetically modified organisms should apply to traditional state liability.

\subsection{Liability for Damage Caused by Unintentional Transboundary Movement}

According to the working definition of "unintentionally caused transboundary movement" proposed by the eighth meeting of the Conference of the Parties to 
the Cartagena Protocol on Biosafety, "damage caused by unintentional transboundary movement" refers to the GMO released within a certain contracting country The living beings have inadvertently crossed the borders of the State Party, resulting in transboundary movement (CBD, 2016). The provisions of Article 17 of the Protocol shall be applied to such transboundary movement only when the living genetically modified organisms involved may have a significant harmful impact on the conservation and sustainable use of biological diversity.

For unintentional transboundary movements, Article 17 of the Protocol provides for emergency measures, that is, each Party shall take appropriate measures upon learning that the following situations have occurred, and send information to the affected or potentially affected countries and biosafety information The clearing house shall also notify relevant international organizations as appropriate: the release caused by an event within its jurisdiction has caused or may result in the unintentional transboundary movement of genetically modified organisms, which may affect biodiversity in the aforementioned countries. Conservation and sustainable use have significant adverse effects and may also pose risks to human health in these countries. Contracting parties shall issue such notifications immediately when they become aware of the above-mentioned circumstances. This article stipulates the notification and advisory requirements regarding the release of genetically modified organisms that are unintentionally transferred across borders that cause or may have significant adverse effects. Parties must provide relevant detailed information and a contact point for further information to the Biosafety Clearing House.

The definition of damage caused by unintentional transboundary movement points out that unintentional transboundary movement is not authorized by the state and the authorities have not been notified, so this is a dangerous activity and should be subject to transboundary damage liability.

\subsection{Liability for Damage Caused by Illegal Transboundary Movement}

Article 25, paragraph 1, of the Protocol provides the definition of illegal transboundary movement. "Illegal transboundary movement" refers to the transboundary movement of genetically modified organisms that violates the domestic measures taken by the relevant contracting party to implement the Protocol. These are "transboundary movements of genetically modified organisms carried out in violation of their domestic measures to implement this Protocol". It is worth noting that the basis for judging whether a transboundary movement is illegal is the domestic measures taken by the State party to implement the "Protocol", rather than directly referring to the provisions of the protocol itself. This seems to recognize the flexibility and discretion of States parties in implementing the Protocol. The domestic measures mentioned here mean that the protocol does not provide a universal standard to measure the legality of transboundary movements. The higher the standards stipulated by the domestic legislation of a 
contracting party, the more likely it is to conduct illegal transboundary movements. The same transboundary movement may be deemed legal in one country and illegal in another country. Therefore, for every transboundary movement of genetically modified genes within the scope of the Protocol, the domestic legislation of the importer and exporter and any transit party must be considered.

Since illegal transboundary movement violates the domestic law of a contracting party. Therefore, civil liability should be applied to damage caused by illegal transboundary movement of genetically modified organisms.

\section{Conclusion}

In order to solve the problem that a single pattern of liability cannot fully solve the problem of accountability and compensation, the "Supplementary Protocol" adopts an open attitude towards the three patterns of liability. The transboundary damage of genetically modified organisms relies on the mechanism of gene drift, and gene drift is achieved through specific vectors, including but not limited to airflow, water flow, food, etc. The transboundary damage of genetically modified organisms has both the characteristics of air pollution, water pollution and other pollution. Thus, the transboundary damage of genetically modified organisms is so complicated, so it is necessary to be open to the application of different patterns of liability to avoid liability gaps. In order to realize timely and adequate compensation for victims of transboundary damage from genetic pollution, it is necessary to classify transboundary damage from genetically modified organisms to apply different liability patterns. To classify the transboundary damage of genetically modified organisms, it is necessary to consider factors, such as the source of the damage, the risk of behavior, and the judgment of causality. Although we propose a new path of liability application for transboundary damages of genetically modified organisms, this classification and application we suggested need to be clarified by legislation. The attitude of the Convention on Biological Diversity and its protocols is to hope that countries will carry out relevant domestic legislation, and after absorbing the experience of domestic legislation, refine genetically modified organisms at the level of international law.

\section{Conflicts of Interest}

The author declares no conflicts of interest regarding the publication of this paper.

\section{References}

CBD (2016). Decisions of the Eighth Meeting of the Conference of the Parties to the Convention on Biological Diversity Serving as the Meeting of the Parties to the Cartagena Protocol on Biosafety. The Secretariat of the Convention on Biological Diversity Montreal.

ILC (2001). Report on the Work of the Fifty-Sixth Session of the International Law Commission (p. 92). 
ILC (2002). Work Report of the Working Group on International Liability for Harmful Consequences Resulting from Acts Not Prohibited by International Law (p. 4).

ILC (2006). Report on the Work of the Fifty-Eight Session of the International Law Commission (p. 72, p. 77).

Isaac (2001). Oxford Dictionary of Scientists (p. 737). Shanghai: Shanghai Foreign Language Education Press.

IUCN (2003). Environmental Law Centre. An Explanatory Guide to the Cartagena Protocol on Biosafety. An Explanatory Guide to the Cartagena Protocol on Biosafety. IUCN Publications Services.

Lin, C. L. (2011). Selected International Environmental Treaties (p. 428, p. 432). Beijing: Academy Press.

Liu, X. X. (2011). Research on the Dynamics of Legislation on the Coexistence of GM Crops and Non-GM Crops-From the Perspective of the U.S., Japan and Europe's Response to GMO Incidents. Life Sciences, 2, 216-220.

Wang, H. (2016). Research on the International Law of the Transboundary Movement of Genetically Modified Organisms (p. 56). Beijing: China University of Political Science and Law Press.

Watanabe, M. E. (2015). The Nagoya Protocol on Access and Benefit Sharing: International Treaty Poses Challenges for Biological Collections. BioScience, 65, 543-550. https://doi.org/10.1093/biosci/biv056

Yang, G. (2014). FAO: Increasing Cases of Genetically Modified Pollution. Pesticide Market Information, 10, 39. 